\title{
A new closing-net for horizontal use, with a suggested method of testing the catenary in fast towing.
}

\author{
By \\ Henry B. Bigelow, \\ Museum of Comparative Zoology, Cambridge Mass.
}

With 8 Text-figures.

Numerous attempts have been made to perfect a closing-met for horizontal towing, a historical resumé of which has been given by Kofoid, ${ }_{1}^{1}$ probably the most successful being the one devised by Kofoid himself, and in use at the Biological Laboratory at San Diego, California. But although the Kofoid net answers the prime requisites of positive opening and closing at the will of the operator, an unobstructed mouth, and the possibility of locating approximately the level at which it is towed, it is so heavy that it can be operated only on strong wire cable by a powerful engine. Its manufacture is complex and expensive; the cost of the improved model being about three hundred dollars. Furthermore it is adapted for slow towing only.

A closing-net for horizontal work which should be so simple that it could be made by any mechanic from stock materials, and as handy to use as an ordinary tow-net, but which, at the same time, could be opened and closed positively at will, independent of the action of the ship, with a mouth little if any more obstructed than that of an ordinary tow-net, would be very desirable apparatus. And though a considerable weight, keeping the towing angle of the rope small, is desirable to allow an approximate estimate of the level at which the net is operating, the operation would be much simplified if the weight be attached to the wire rope, of course close to the point of attachment of the net, thus allowing the frame of the latter to be light. During the summer of 1911 , experiments, with this end in view, were carried out at sea, through the courtesy of Mr. Joseph S. Bigelow Jr., who allowed the use of his yacht; and the apparatus described below is the result of two preceding experimental models. The net was made by the International Instrument Co., of Cambridge, Mass., to whose officers I am indebted for valuable suggestions.

1) University of California Publ. Zool. 1911, Vol. 8, p. 312-340, pl. 22-24. 
The net is a combination of the Chun-Petersen-Nansen principles, i. e., it has a hinged ring which is sent down closed, to be opened by messenger; and closed by a draw string about the net-bag, likewise operated by messenger, but various modifications were required for horizontal use. In the first model the drag of the bag was depended upon to open the mouth. But it proved absolutely necessary to have some mechanical device to insure the simultaneous opening of the two sides of the frame; otherwise one usually opened first, the other remaining closed.

Net frame. The frame (Fig. 1, 2) when open, is circular, hinged, $75 \mathrm{~cm}$ in diameter and as in the Chun-Petersen net the four-fold towing bridle is replaced in part by a metal bail of round brass, $6 \mathrm{~mm}$ in diameter. Each half of the frame bears an arm, near the middle of its length, to which the other two parts of the bridle, of $3 \mathrm{~mm}$, phosphor-bronze cord, are attached,

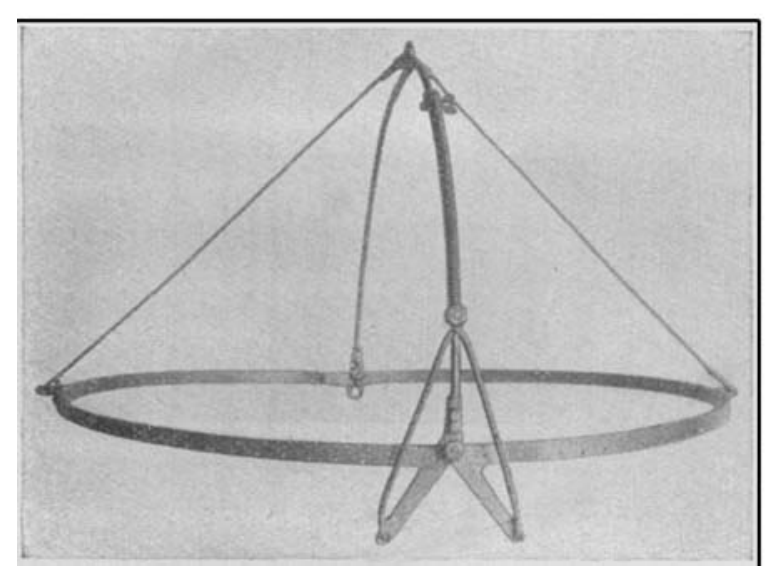

Fig. 1. The net frame closed.

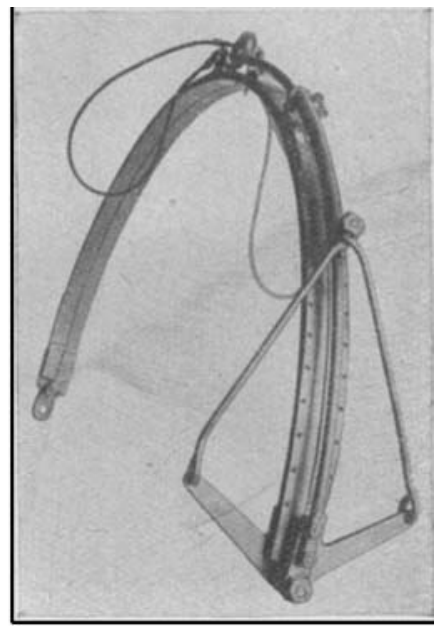

Fig. 2. The net frame open.

these arms preventing the halves of the frame from swinging in the wrong direction past the mid-line. The frame is opened by a long spiral spring of phosphor-bronze wound around the bail, acting upon two distance-rods. One end of each of these is linked to a perforated rider travelling freely on the bail, while at the other, each is connected with an arm, which extends obliquely from one of the halves of the frame, close to the hinge joint. The spring is held under tension by a second rider sliding on the bail, fastened in place by a thumb-screw; which is loosened, so that the spring released is from tension, when the net is not in use. At the top of the frame, just below the loop in the bail. one side bears a latch over lapping the other (Fig. 5), and a locking-pin passes through the two, holding the frame shut when the spring is set.

To ensure that nothing enters the net on the way down, the edges of the jaws must either fit together accurately, or they can be beveled, or lined with felt as in the Chun-Petersen net. But the latter precaution is Revue d. ges. Hydrobiol. u. Hydrogr. Bd. V. H. 5/6. 
advisable only when the micro-plankton is the object of research. The closing cord is merely a girdle with slip-ring surrounding the bag, shutting off the lower end of the latter when drawn taut, a method of closure which has proved perfectly satisfactory in the Nansen net.

The operation of the net depends on the tow line and on the tripping gear or lock-plate. The former (Fig. 4) is about $60 \mathrm{~cm}$ long with a terminal

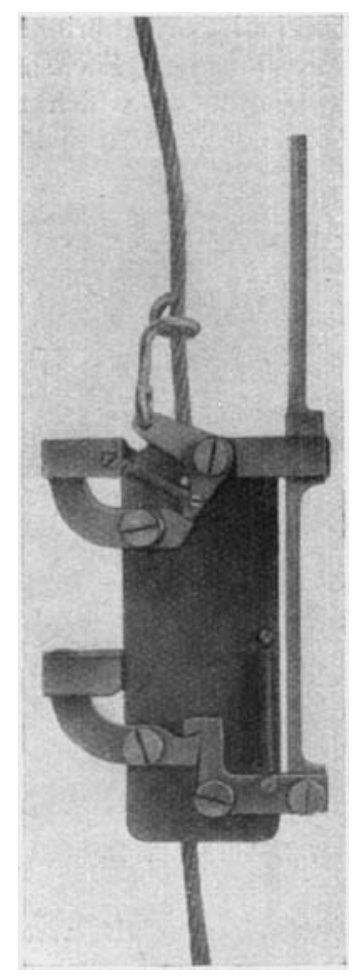

Fig. 3. The lock.

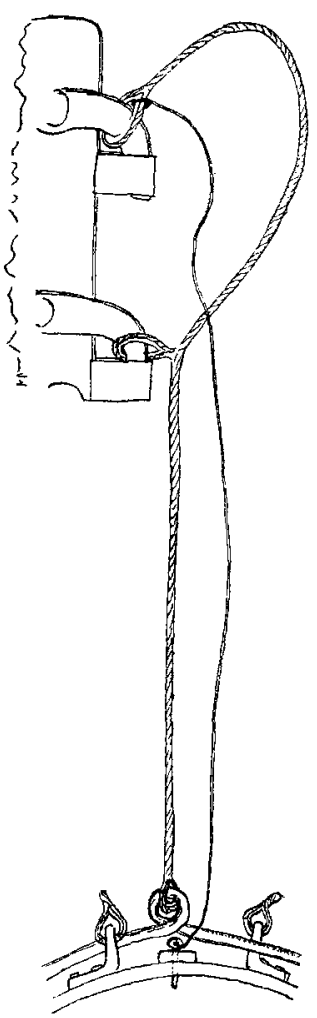

Fig, 4. The towline, connected with the lock, with the net closed ready to be sent down.

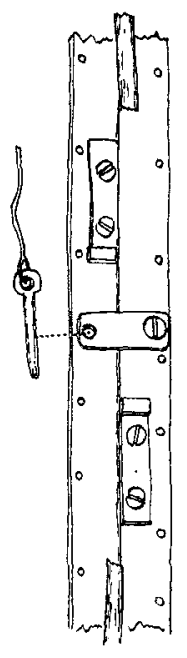

Fig. 5. Midportion of the closed frame, with the central section of the bail omitted, to show the latch and locking pin.

loop, and another midway of its length, the locking-pin cord, about $45 \mathrm{~cm}$ long, being fastened to the terminal loop. If this cord is of the correct length, no strain will come on it when the net is towed from the median loop; but when the net is towed from the terminal loop, the whole drag will come first on the lock-pin cord, and the pin will be pulled out, allowing the net to open.

The tripping gear (Fig. 3), consists of a brass plate, $20 \mathrm{~cm}$ long, $10 \mathrm{~cm}$ broad, and $6 \mathrm{~mm}$ thick. On one face it bears two locks, each of three 
members, hook, scear, trigger, an arrangement based on the ordinary gunlock, which combines great strength with reliability. At the outer ends the hooks are clasped by bifid arms projecting from the edge of the plate, which prevent the loops of the tow line from slipping off when the locks are set. But when the scears are released by the impact of the messengers on the triggers, the hooks are free to fall, either by their own weight or from the drag of the net: and they are so shaped that the loops slip off freely. The upper trigger is linked to the scear and looped around the dredging rope in a spiral sufficiently open to allow the latter to be inserted or removed readily: the lower trigger is offset opposite the top of the lock-plate about inches, and on the opposite face the plate bears two clamps, to fasten it to the rope. The messengers are of the shape shown in the figures.

The net-bag can be of any desired material: and any type of plankton bucket adapted to horizontal towing can be used.

Mode of operation. The frame is closed, the locking-pin placed in position; the spring set up hard, and the rider locked in placed on the bail. The lock-plate is then clamped to the dredging rope preferably about two feet above its end: and the appropriate weight attached to the ring in the end of the latter. The median loop of the tow line is then engaged on the upper lock-hook, and the latter raised, which automatically sets the lock; the terminal loop of the tow line being similarly connected to the lower hook. The free end of the closing-cord is then fastened to the loop at the end of the dredging rope, and the net is ready to lower. To avoid any chance of the net-bag fowling, or twisting around the rope on the way down, the vessel should be moving at her towing speed before the apparatus is put over the side, and kept under headway throughout the operation. As soon as the bag is trailing astern, and all is clear, the rope is payed out to the requisite depth. The smaller messenger is then sent down. This springs the upper lock, releasing

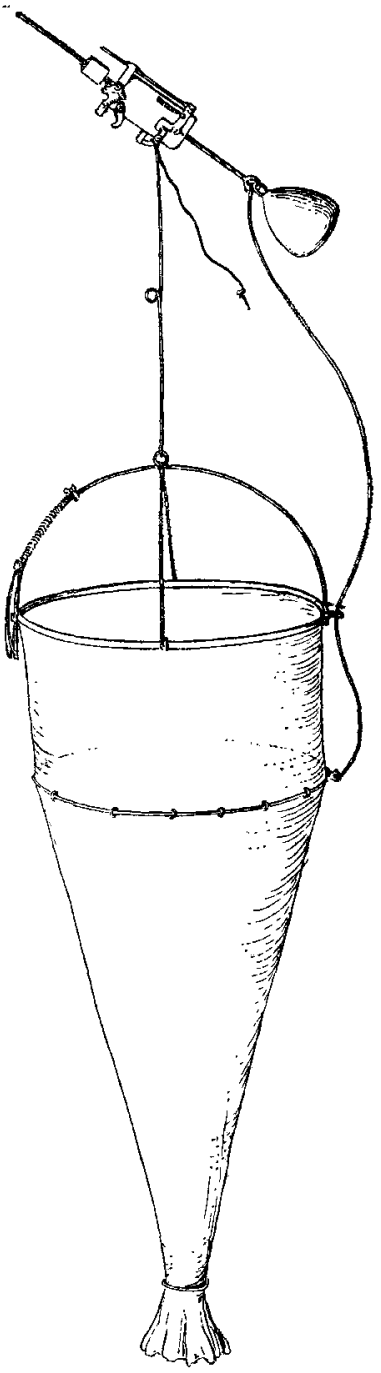

Fig. 6. The net being towed. the median towloop. The drag of the net then comes directly on the lockpin cord, the lock-pin is pulled out, and the spring opens the net, which tows from the terminal loop of the tow line. To close the net, the large messenger is sent down, which releases the tow line altogether, so that the strain comes on the closing-cord; this closes the bag exactly as in the 
Nansen net. The net is then hauled up. In practice it has proved convenient to pass the closing cord through a large oye close to one hinge of the frame: in this way the latter is brought up edgewise. The advantages of this net are.

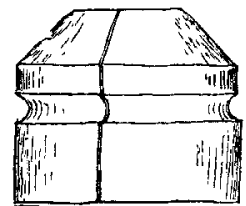

Fig. 7. The first messenger about $1 / 4$ nat. size.

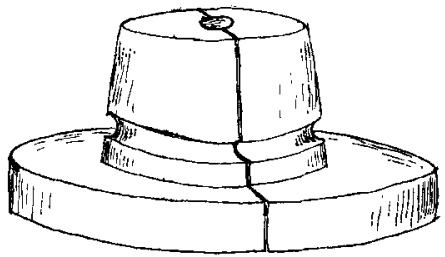

Fig. 8. The second messenger.

1. Simplicity. 2. Leight weight: frame, $12 \mathrm{lbs}$. 3. Cheapness: the frame, lock-plate and messengers costing about filty dollars. 4. Positive closing and opening at the will of the operator, with perfect closure during descent and ascent. 5. Simplicity of operation; with possibility of fast towing. 6. Possibility of making the frame very much larger.

Its disadvantages are

1. The fact that the mouth is not wholly free from obstruction: but this. difficulty is chiefly academic, because the lock-plate, travelling edgewise in the water, has a frontal area of only about $5 \mathrm{sqw} . \mathrm{cm}$, and the bail need be no stouter than the members of the ordinary rope bridle. 2. Chance of fowling the net-bag while lowering. But this is remote unless clumsily handled.

A knowledge of the level at which the net is towed, at least as close as the limits of a vertical haul, is of course essential. And as Kofoid ${ }^{1}$. has pointed out, the data afforded by the length of the towing rope and its angle does not allow this to be calculated closely if the obliquity is great, because the catenary is always an unknown quantity. His solution of this difficulty has been to keep the rope nearly vertical by using a very heavy net; but this is possible only if it is towed very slowly. With faster towing, and considerable obliquity of the rope, a better index of depth than the visible angle of the rope itself would probably be afforded by the angle of a sounding wire attached to the end of the rope sent down through the dredging-pulley with the latter, and then hauled in taut, almost to the breaking point. The wire would be independent of the drag of the net; and there would be only its resistance to the water and its small weight to. give it any catenary, Down to 300 fathoms or so the second factor would be negligible, and experience in sounding at various depths suggests that the first would have so little effect if the wire were kept under a strain of say 50 lbs., that the data afforded by its angle and outboard length would locate the net within much closer limits than those of a vertical haul. Experiments with this method will be carried on this summer.

1) Loc. cit. 